\title{
El documental en el contexto de la televisión pública. Categorías para su análisis
}

\author{
Alberto Alejandro Alzate Giraldo*, Claudia María Maya Franco**, Verónica Heredia Ruiz ${ }^{* * *}$ \\ DOI: https://doi.org/10.33571/revistaluciernaga.v12n23a6
}

\section{Resumen}

El artículo aborda el lugar que ocupa y la naturaleza que asume el documental en el contexto de la televisión pública. Para esto plantea un instrumento de análisis y caracterización del formato documental. Éste articula tres enfoques: la perspectiva del discurso, las características del formato documental y las funciones de la televisión pública. Tiene múltiples perspectivas de análisis y puede ser utilizado en diferentes corpus audiovisuales. Se obtuvo una caracterización detallada de los documentales analizados, así como de sus modalidades expresivas y discursivas.

Palabras clave: Televisión pública; documental; análisis del discurso; audiovisual.

Recibido. Febrero 18, 2020

Aceptado. Marzo12,2020

\footnotetext{
*Docente - investigador, Facultad de Comunicación, Universidad de Medellín. Coordinador Centro de Investigación de la misma universidad. Doctor en Estudios Avanzados de Arte Contemporáneo, Facultad de Bellas Artes, Universidad de Barcelona. Master en Antropología Visual. Máster en investigación y producción artística Universidad de Barcelona. Orcid: https://orcid.org/0000-0002-1634-9982 ; e-mail: alejandroalzateg@gmail.com

${ }^{* *}$ Profesora Facultad de Comunicación, Universidad de Medellín. Doctora en Filosofía UPB, Magíster en Filosofía UdeA, Especialista en Psicoanálisis y Filosofía, EAFIT, Licenciada en Filosofía UPB. Orcid: https://orcid.org/0000-0003-2617-5661 ; e-mail: cmaya@udem.edu.co

***Docente - investigadora Facultad de Comunicación, Universidad de Medellín. Jefa de Programa de Comunicación y Lenguajes Audiovisuales de la misma universidad. Magíster en Comunicaciones y Comunicadora Social- Periodista UDEA. Orcid: http://orcid.org/0000-0002-5677-6479; e-mail: vhruiz@udem.edu.co
} 


\title{
The documentary in the context of public television. Categories for analysis
}

\author{
Alberto Alejandro Alzate Giraldo*, Claudia María Maya Franco**, Verónica Heredia Ruiz***
}

DOI: https://doi.org/10.33571/revistaluciernaga.v12n23a6

\begin{abstract}
The article addresses the place and nature of the documentary in the context of public television. For this purpose, it proposes an analysis and characterization instrument for the documentary format. It articulates three approaches: the perspective of discourse, the characteristics of the documentary format and the functions of public television. This instrument has multiple perspectives of analysis and can be used in different audiovisual corpus. It was achieved a detailed characterization of the analyzed documentaries, as well as their expressive and discursive modalities.
\end{abstract}

Keywords: Public television; documentary; discourse analysis; audiovisual.

Received. February 18, 2020

Accepted. March 12, 2020

\footnotetext{
*Professor-Researcher, School of Communication, Universidad de Medellín. Coordinator of the Research Center in the same university. PhD in Advanced Studies of Contemporary Art, Faculty of Fine Arts, University of Barcelona. Master in Visual Anthropology. Master in research and artistic production, University of Barcelona. Orcid: https://orcid.org/0000-0002-1634-9982 ; e-mail: alejandroalzateg@gmail.com

** Professor, Faculty of Communication, Universidad de Medellín. PhD in Philosophy UPB, Master in Philosophy UdeA, Degree in Psychoanalysis and Philosophy, EAFIT, Degree in Philosophy UPB. Orcid: https://orcid.org/0000-0003-2617-5661 ; e-mail: cmaya@udem.edu.co

*** Professor - researcher, Faculty of Communication, Universidad de Medellín. Head of the Communication and Audiovisual Languages Program at the same university. Master in Communications and Social Communicator- Journalist UdeA. Orcid: http://orcid.org/0000-0002-5677-6479 ; e-mail: vhruiz@udem.edu.co
} 


\title{
O documentário no contexto da televisão pública.
}

\section{Categorias para análise}

\author{
Alberto Alejandro Alzate Giraldo*, Claudia María Maya Franco**, Verónica Heredia Ruiz ${ }^{* * *}$ \\ DOI: https://doi.org/10.33571/revistaluciernaga.v12n23a6
}

\section{Resumo}

O artigo discute o lugar e a natureza dos documentários no contexto da televisão pública. Para tal, propõe um instrumento para a análise e caracterização do formato documental. Articula três abordagens: a perspectiva do discurso, as características do formato documental e as funções da televisão pública. Tem múltiplas perspectivas de análise e pode ser utilizado em diferentes corpus audiovisuais. Foi obtida uma caracterização detalhada dos documentários analisados, bem como as suas modalidades expressivas e discursivas.

Palavras-chave: Televisão pública; documentário; análise do discurso; audiovisual.

Recebido. 18 de Fevereiro de 2020

Aceitado. 12 de Março de 2020

\footnotetext{
* Docente-pesquisador, Faculdade de Comunicação, Universidade de Medellín. Coordenador do Centro de Investigação da mesma universidade. Doutoramento em Estudos Avançados em Arte Contemporânea, Faculdade de Belas Artes, Universidade de Barcelona. Mestrado em Antropologia Visual. Mestrado em investigação e produção artística, Universidade de Barcelona. Orcid: https://orcid.org/0000-0002-1634-9982 ; e-mail: alejandroalzateg@gmail.com

${ }^{* *}$ Professor, Faculdade de Comunicação, Universidade de Medellín. D. em Filosofia UPB, Mestre em Filosofia UdeA, Especialista em Psicanálise e Filosofia, EAFIT, Licenciado em Filosofia UPB. Orcid: https://orcid.org/0000-0003-2617-5661 ; e-mail: cmaya@udem.edu.co

*** Docente e investigador, Faculdade de Comunicação, Universidade de Medellín. Chefe do Programa de Comunicação e Linguagens Audiovisuais na mesma universidade. Mestre em Comunicação e Comunicador Social - Jornalista UdeA. Orcid: http://orcid.org/0000-0002-5677-6479; e-mail: vhruiz@udem.edu.co
} 


\section{Introducción}

El presente artículo propone y describe un instrumento para el análisis de documentales en la televisión pública. Se trata del resultado preliminar de la investigación: Construcciones discursivas de la memoria, las identidades y las ciudadanías en la televisión pública a través del formato documental. Caso: Canal Telemedellín, período (1997 - 2014).

En primer lugar, se presenta de manera breve las categorías y los conceptos que componen este instrumento, así como su justificación. En segundo lugar, se expone la metodología y en tercer lugar los resultados obtenidos a partir de su aplicación, específicamente en lo relativo a las perspectivas de análisis que lo constituyen: análisis del discurso, formato documental y televisión pública.

Con este análisis se espera una mejor caracterización del tipo de documental que se está produciendo y transmitiendo en la televisión pública. Ésta se enfoca a sus modalidades expresivas, sus contenidos, y el modo en que se relaciona con el contexto, esto es, con sus condiciones de producción y recepción en un canal de televisión.

\section{Conceptos y perspectivas del análisis. Teoría de la enunciación}

La Teoría de la Enunciación (Charaudeau, 1993) además de explicar el acto comunicativo en términos de una relación contractual y estratégica, amplía el modelo clásico compuesto por emisor, destinatario y canal. A este modelo, o circuito externo, empírico de la comunicación, añade un circuito interno, que constituye un mundo discursivo, configurado de acuerdo con las necesidades del Yo comunicante, un nuevo espacio en el que existen, no solo seres reales, de carne y hueso, sino sujetos discursivos. Así, el Yo enunciador existe en tanto actualiza el discurso y es responsable de sus efectos sobre un destinatario. A su vez, el sujeto interpretante es discursivo; un interlocutor, fabricado por el sujeto enunciante como el destinatario ideal de su discurso. A su cargo está la interpretación.

La teoría de la enunciación resulta relevante toda vez que permite avanzar hacia una caracterización del documental en el ámbito de la televisión pública, toda vez que reconoce los diversos sujetos que en los documentales visualizados participan de la interacción, así como el modo en que éstos los constituye en tanto sujetos. Lo anterior incide, por supuesto, en el aspecto narrativo de los documentales. No es lo mismo una voz en off omnisciente que la historia a la que se accede a través de un diálogo, entrevista, documento histórico, testimonio. A su vez, estas modalidades de la enunciación, y otras todavía, determinan la representación o, siguiendo a Pedro Adrián Zuluaga (Silva \& Kuellar, 2015, pág. 71) auto representación que cada documental se propone, esto es, su punto de vista, su nivel de compromiso, su apego o distancia respecto de la "verdad", su estatuto estético, su función social.

Esta perspectiva también permite la pregunta por los destinatarios. El auditorio, en términos de la retórica, es una construcción del orador, en este caso, del director, de modo que es susceptible de objetivación concreta y, a su vez, de caracterización. Otro tanto pasa con las demás preguntas: ¿Dónde? ¿Cuándo? ¿Con qué propósito? son preguntas que esbozan el contexto, tanto empírico como discursivo de la enunciación documental, así como sus finalidades. 


\subsection{Dimensiones emocional y racional de la argumentación}

La segunda perspectiva, también de Charaudeau (2011), se orienta al componente emocional de la argumentación. Según el autor, en todo discurso existe una dimensión racional y lógica, en relación con la cual es posible interrogar por la validez de los argumentos a la hora de demostrar o convencer; y emocionar, o psicológica, en donde lo que se pone en juego es el carácter persuasivo de los argumentos. Estos componentes no entran en juego de modo separado; una demostración convincente puede ser, a su vez, elocuente y suscitar efectos emocionales en el auditorio. Así mismo, las emociones suscitadas pueden reforzar la adhesión respecto de determinados puntos de vista. Interesa, en este punto, poner de manifiesto, en los documentales que constituyen el corpus de análisis, la presencia de estas dimensiones así como la proporción entre las mismas, en aras de una más clara caracterización de las estrategias persuasivas utilizadas.

\subsection{Funciones del lenguaje en el documental}

En tercer lugar, se utiliza una de las más conocidas caracterizaciones de la comunicación verbal, a saber, la ofrecida por Jakobson (1981). Según ésta, el lenguaje posee diversas funciones entre las más evidentes, la referencial, que se centra en el tema del que se habla a través de oraciones declarativas o enunciativas. Es esta función la que con más frecuencia privilegian los estudios sobre documental. Sin embargo, también se dirige la mirada hacia las otras funciones trabajadas por Jacobson, a saber, la función poética, emotiva o expresiva, que suele atribuirse a la poesía y cuya referencia es la intimidad; la conativa o apelativa, orientada al auditorio y cuyo referente es el tú; la metalingüística, que se centra en el código lingüístico; y la fática, que inicia, interrumpe, continúa, finaliza. El propósito consistió en el análisis, en virtud de la modalidad del contrato, del tipo de sujetos empíricos y discursivos que emergen, y de las funciones del lenguaje que se actualizan en los documentales mediante ciertas tendencias discursivas que inciden directamente en el mensaje audiovisual y en sus efectos.

\subsection{El documental}

Como lo expresa Rabiger (2005) el documental es un fragmento de la realidad visto a través del temperamento humano. Como contenido, el documental nació en el cine y llega posteriormente a la televisión, y es a través de este formato que se da cuenta de la realidad de las historias de los ciudadanos de una localidad, región o país. Como sostiene Rincón (2006) "Contar la vida real siempre ha sido una obsesión del hombre; contarla en versiones inéditas es la invención del documental" (Pág. 188).

La definición de su concepto parte de un proceso histórico que se ha transformado a través del tiempo, que pasa por las categorías planteadas por Nichols (1997), los cambios provenientes del uso del documental desde los años 60 con la llegada del cinema verité visibilizado por Jean Rouch (López, 2011), hasta manifestaciones más recientes como el documental etnográfico (Ardevol, 2008) y los cambios planteados en la última década a través del documental transmedia (Gifreu, 2012).

El documental ha sido clasificado a través de diversas tipologías, así en la propuesta de Nichols, (1997) tenemos las siguientes: expositivo, observacional, reflexivo, poético y performativo, además del documental etnográfico y el interactivo, web o transmedia. La categoría expositiva ha sido la predominante desde sus inicios, implementa comentarios que van dirigidos al espectador y usa las imágenes como ilustración de los contenidos. La modalidad observacional, a diferencia de la expositiva, intenta ser un testigo de lo que está sucediendo, la cámara actúa como un observador, 
contrastando los recursos usados en la modalidad expositiva. El modo reflexivo se caracteriza por presentar las situaciones y dar predicciones sobre los temas tratados, mientras que, en lo performativo, la presencia del autor ante la cámara y la autoreferenciación son los indicadores de la existencia de dicha categoría. El modo poético se caracteriza por una narración no lineal y más experimental del mundo histórico.

El documental etnográfico se caracteriza por incluir la cámara en el centro de la acción y hacerla participativa, sin concentrar la atención en entrevistas eruditas (Ardevol, 1998). Por su parte, la modalidad interactiva, web y transmedia incorpora diferentes estrategias narrativas, especialmente un punto de encuentro entre el espectador y el realizador. En este caso se privilegia la interacción, o nuevas formas convergentes de presentar el contenido a la audiencia.

Además de la clasificación presentada, que da cuenta de unos mecanismos estéticos y narrativos de organización del contenido documental, para efectos de esta investigación se entiende también un formato televisivo. Lo anterior significa que el documental, es entre otros, una posibilidad de empaquetamiento de los contenidos televisivos para contar una historia, o destacar ciertos temas de interés para el público. Sus características narrativas como programa en televisión se fundamentan en los siguientes elementos planteados por Rincón (2006): la realidad está ahí para ser contada, su potencial y valor está en llamar la atención pública sobre la realidad no televisiva, tiene valor porque produce impacto emocional, genera conversación cotidiana y tiene actualidad pública y es un lugar de experimentación estética y narrativa. (Pág. 189-190)

La gran paradoja es también que el documental ha sido uno de los formatos más olvidados por la televisión comercial, y por eso la televisión pública está llamada a recuperar este tipo de contenidos en la pantalla.

\subsection{Televisión Pública: pantalla de reconocimiento ciudadano}

Una de las premisas fundamentales que guía la discusión para entender la televisión pública es que ésta se dirige a los ciudadanos más que a los consumidores (Rincón, 2005). En este sentido, la televisión es entendida como servicio y bien público, en la medida que ofrece contenidos e información útil que beneficia a todos los ciudadanos. De hecho, la importancia de la televisión pública en las sociedades modernas radica en que ésta promueve la participación ciudadana, el sostenimiento de la diversidad cultural y la defensa de la libertad de expresión como base para la democracia.

Es así, como esta investigación se apoya en el concepto de televisión pública, de una serie de autores latinoamericanos recogidos en el texto "Televisión Pública, del consumidor al ciudadano", donde Rincón (2005) en su rol de autor y compilador, reúne los análisis de Martín - Barbero, Cifuentes, Rey, Fuenzalida, Mazzioti, Orozco, Otondo, Portales Montero sobre las principales reflexiones y conceptos para entender la televisión pública, y como un tema prioritario en la agenda social y política de América Latina. Su planteamiento básico es que este tipo de televisión tiene un rol preponderante en la sociedad, es una pantalla para el reconocimiento de las audiencias, en su calidad de ciudadanos, y es allí, en ese escenario de lo público, donde encuentran los temas de interés, la información que la gente necesita para la toma de decisiones en el ejercicio de la democracia.

De hecho, el debate por el concepto de televisión pública también ha sido abordado por autores Keane (1993), Fuenzalida (2000), Waisbord (2000), Williams (2003), Dahlgren (1995) (1997) (2009), Livingstone \& Lunt (1994), Keane (1985) (1997), Thompson (1996) (1998), Barker (2003).e incluso 
la propia UNESCO (2006) se ha pronunciado frente al tema. En términos generales, los autores y la entidad coinciden en plantear que la televisión, sea esta pública o privada, es una sola y debe atender tres funciones sustantivas: informar, educar y entretener. $Y$ en el ejercicio de estas funciones, la televisión pública es sin lugar a dudas la mejor pantalla procesos de identificación, apropiación, reconocimiento y participación de las audiencias en su rol de ciudadanos, y en la construcción de la opinión pública.

Es así como Dahlgren (1995) conecta la televisión con el concepto de esfera pública de Habermas, destacando el rol de los medios en las sociedades modernas y su relación con la democracia. En este sentido, la televisión como esfera pública se convierte en un espacio de interacción de los ciudadanos y para los ciudadanos con los procesos políticos, donde la información, las ideas y el debate circulan para configurar la opinión pública.

De acuerdo con lo anterior, la televisión entendida desde su dimensión pública, promueve el ejercicio de la democracia y la ciudadanía, porque le da criterios a la gente para la toma de decisiones; además refuerza a través de la diversidad de su programación, elementos de la identidad y la diversidad cultural, así como el reconocimiento de las audiencias y su participación en los contenidos.

En este orden de ideas, la televisión pública privilegia el carácter de servicio público. Lo anterior, ha significado una división entre la televisión de propiedad privada y con fines comerciales, y aquella de carácter público, de propiedad Estatal, con fines sociales. De hecho, Mazzioti (2005) expresa que es claro que la televisión pública debe diferenciarse de la televisión de carácter comercial, y que su propósito fundamental es dirigirse a la ciudadanía. Para ello, señala que la televisión de este tipo requiere "asentarse en una programación de calidad; hacerse cargo de lo que deja vacante la televisión comercial y necesita tener en cuenta la diversidad cultural, la tolerancia y la apertura hacia otros sujetos culturales." (págs. 184-185)

Precisamente, Rincón (2005) destaca que "comprender la televisión significa entendernos como sociedad, mirarnos como ciudadanos, pensarnos como audiencia" (pág. 21). Es por esto que la televisión pública, es definida en este sentido, como un servicio de carácter público, gratuito y útil para los ciudadanos; con pluralidad de contenidos, rigurosidad en el abordaje de la información, que apela a criterios como independencia, neutralidad y garantía de acceso para todos.

Otro de las características importantes de la televisión pública, es la que señalan Castaño \& Cardona (2012), cuando destacan que uno de sus valores fundacionales es la identidad, ya que a través de este medio se difunden los valores y tradiciones integradoras de una colectividad nacional. Por su parte, para Igárzabal (2013) definir la televisión pública abarca "un conjunto de variados modelos de canal, de programación y de financiamiento (...). desde ella se deben mostrar las diferentes identidades y la heterogeneidad de la sociedad" (Pág. 58). Señala esta autora una serie de constantes en América Latina en lo que se refiere a televisión pública: está acompañada de bajos presupuestos y presiones políticas; y una concepción de cultura y lo popular alejado de sus audiencias.

Por su parte, la Unesco (2006) define que el rol principal que cumple la televisión pública es proporcionar a los ciudadanos el acceso y la participación a la vida pública, además de facilitar el acceso a la educación y la cultura. En este orden de ideas, la televisión pública se caracteriza porque se dirige a todos los públicos, especialmente a las minorías, busca el reconocimiento, la inclusión social a través de contenido variado y de calidad que refleje las necesidades, preocupaciones, expectativas de diversas audiencias. (UNESCO, 2006, pág. 28) 
La UNESCO (2006) defiende y destaca por su parte que la Radiotelevisión de Servicio Público (RSP) cumple funciones muy importantes para el ejercicio de una ciudadanía responsable, que incide en la toma de decisiones de las comunidades "porque permite a la gente informada adoptar decisiones vitales para su propio desarrollo". (UNESCO, 2006, pág. 6). Y agrega la UNESCO que son funciones de la Televisión Pública:

Universalidad: La televisión pública debe estar al alcance de todos los ciudadanos del país. Sus contenidos se dirigen a todos, independientemente de su nivel socio-económico.

Diversidad: Hace referencia a la variedad de contenidos en función de los géneros y formatos de programas ofrecidos; así como las audiencias a las que se dirige y que los temas discutidos apelen a los intereses públicos de la sociedad.

Independencia: La televisión de servicio público suele confundirse con televisión propagandística del gobierno de turno. Precisamente, la independencia hace referencia a un tipo de televisión que sea un espacio abierto donde las ideas puedan expresarse libremente, y donde pueda circular la información, las opiniones y las críticas de un país.

Diferenciación: Un principio fundamental es que la televisión de servicio público pueda diferenciarse desde sus contenidos de los demás canales. Desde la calidad y autenticidad de la programación la audiencia debe distinguirla de los demás. Esta característica también apela a la innovación, creatividad y nuevas propuestas de programación para las audiencias. (UNESCO, 2006, Págs 31 32)

\section{Canal Telemedellín}

Telemedellín, creado el 13 de agosto de 1996, es un canal local de carácter público, de señal abierta y sin ánimo de lucro. Tiene un área de cobertura en diez municipios del Valle de Aburrá en Antioquia (Colombia) y cuenta con una sede en Medellín llamada Canal Parque Gabriel García Márquez, inaugurada en el año 2015. El Canal fue creado mediante la figura de asociación canal local de televisión, en el gobierno del alcalde Sergio Naranjo Pérez (1995-1997), conformado por entidades públicas del orden municipal así: la Alcaldía de Medellín, el Área Metropolitana, Instituto de Deportes y Recreación de Medellín (INDER), Empresas Varias de Medellín (EEVV) y el Instituto Tecnológico Metropolitano de Medellín (ITM).

Telemedellín es uno de los 24 canales sin ánimo de lucro de Colombia (ANTV, 2015) y está regido por el Acuerdo $\mathrm{N}^{\circ} 24$ de la Comisión Nacional de Televisión, hoy Autoridad Nacional de Televisión ANTV, entidad gubernamental en Colombia encargada de la ejecución de los planes y programas de la prestación del servicio público de televisión.

El Canal inició sus transmisiones el 7 de diciembre de 1997. Con más de 18 años al aire, ha tenido una vocación de servicio público al abordar en su programación temas de ciudad en el que se destacan dos grandes ejes: la participación y la cultura ciudadana. De hecho, Telemedellín ha tenido dos eslóganes que se han evidenciado en su lenguaje audiovisual, así como en su estética, narrativa, y contenido. Entre el año 1997-2007 fue el Canal de la Cultura Ciudadana, y desde 2008 a la fecha es Aquí te ves.

En su página web, www.telemedellin.tv el eslogan actual "Aquí te ves" se traduce en un manifiesto que se resume en que ciudadanos son los protagonistas, la ciudad es el mejor escenario, los pequeños acontecimientos son noticia y especialmente, que la televisión pública sí puede ser entretenida. 
El exalcalde Aníbal Gaviria comenta que el propósito del canal es "contribuir a la formación de los ciudadanos, para posicionar imaginarios colectivos con el fin de movilizar a la comunidad hacia propósitos comunes" (Telemedellín, 2012). También destaca como características de Telemedellín que es el canal de la comunidad, ventana de la ciudad y voz de quienes la habitan, porque visibiliza los rostros de cada ciudadano. Señala que comunicar es un acto de gobernar, que el canal es un espacio para la participación y el diálogo ciudadano, una plataforma de contenidos locales para conectar a Medellín con el mundo.

\section{Metodología. Presentación del instrumento}

Para la construcción del instrumento y análisis del material de archivo se integraron las categorías propuestas desde la teoría de la enunciación y el análisis de discurso, la clasificación de documental propuesta por Bill Nichols, y las funciones de la televisión pública propuestas por la UNESCO. De cada propuesta se identificaron algunas variables aplicables a la muestra. Para dicho fin se diseñó un instrumento que a su vez hace parte de los resultados de investigación, ya que puede ser ajustado y utilizado en futuros estudios relacionados con la clasificación y categorización de productos documentales.

El instrumento está articulado en cuatro partes para el abordaje de los audiovisuales (Ver Tabla 1). La primera parte contiene la identificación de los documentales, que incluye el código interno, el título, la fecha de realización, y la fecha de emisión, así como a una caracterización relacionada con su duración, clasificación de los contenidos según sean unitarios o serie y el tipo de recursos con el cual fueron realizados, teniendo en cuenta si fueron financiados con recursos externos, internos, públicos o privados. Además, si ha sido realizado en el ámbito nacional o internacional. Dentro de esta clasificación se detalló puntualmente cada una de las personas vinculadas a la producción, teniendo en cuenta sus funciones o roles, para posteriormente identificar las figuras representativas dentro del canal en su historia. Este instrumento incluye la sinopsis, la cual fue en muchos casos construida como parte de las actividades del proyecto de investigación. La primera parte de la identificación contiene un apartado para observaciones y otros temas abordados.

La segunda parte de la clasificación responde a tres elementos del análisis del discurso: En primer lugar, la situación de enunciación, la cual se formula en términos de las preguntas: ¿quién habla? ¿desde dónde? ¿mediante qué recursos? ¿a quiénes? ¿con qué propósito? ¿cuándo? En segundo lugar, el reconocimiento de las dimensiones emocional y racional de la argumentación. En tercer lugar, las funciones del lenguaje (Jakobson) que permite identificar la presencia de la función emotiva, conativa, referencial, metalingüística, fática, poética.

La tercera parte del instrumento corresponde a la clasificación según las modos de representación del documental propuestos por Nicholls (1997), que se refiere al campo expositivo, reflexivo, observacional, poético y performativo. Incluyendo además los cambios narrativos por los que ha atravesado el documental a través del tiempo, como el documental etnográfico (Ardevol, 1998), y el componente interactivo o transmedia (Gifreu, 2012).

La cuarta parte de la ficha está relacionada con las características de la televisión pública según la UNESCO (2006): la universalidad, la diversidad, la independencia y la diferenciación y un campo de observaciones para el equipo investigador, donde se detallan comentarios y observaciones. 


\subsection{Recolección de información y proceso de sistematización}

El Canal Telemedellín suministró una base de datos general con la clasificación de los contenidos documentales realizados por el canal, con un total de 393 registros que comprenden producciones desde el año 1997 hasta el 2014. Posteriormente, se entregaron los documentales digitalizados para el análisis, con un total de 132 piezas audiovisuales que fueron visualizadas por parte del equipo investigador, lo que correspondió a un 34 \% del universo de documentales realizados por el canal desde su creación. A partir de esa base de datos, el equipo investigador realizó una primera identificación, clasificación y visualización del material suministrado aplicando el instrumento de análisis propuesto, y posteriormente se ingresó la información a una base de datos en Excel que permitió la sistematización de la información, y posteriormente su interpretación tanto desde el punto de vista cuantitativo como cualitativo.

\section{Resultados. Hallazgos relativos a la televisión pública}

Desde su creación el Canal Telemedellín le apostó al documental como un formato para narrar la ciudad y los temas de interés para la ciudadanía, lo que corresponde al ámbito y funciones de la televisión pública. Es así como en el período analizado, se encontró una apuesta constante por este tipo de formato, como se puede ver en la Tabla 2.

Precisamente en los primeros años de producción, 1998 y 1999, se registraron 24 documentales, que corresponden a un $19 \%$ de la muestra visualizada, lo que permite inferir que el documental ha sido desde el inicio del Canal un formato adecuado para contar la ciudad, para acercar a los ciudadanos a la nueva pantalla de televisión pública local. Así mismo, los años 2009 y 2010 suman un $42 \%$ de producción documental, siendo este período el de mayor presencia de este formato entre los años 19972014. Se infiere que en estos dos años el canal ya contaba con una madurez narrativa, técnica, estética, de contenidos y financiera que le permitieron hacer apuestas documentales con mayor énfasis.

\section{Tabla 2. Documentales analizados por año}

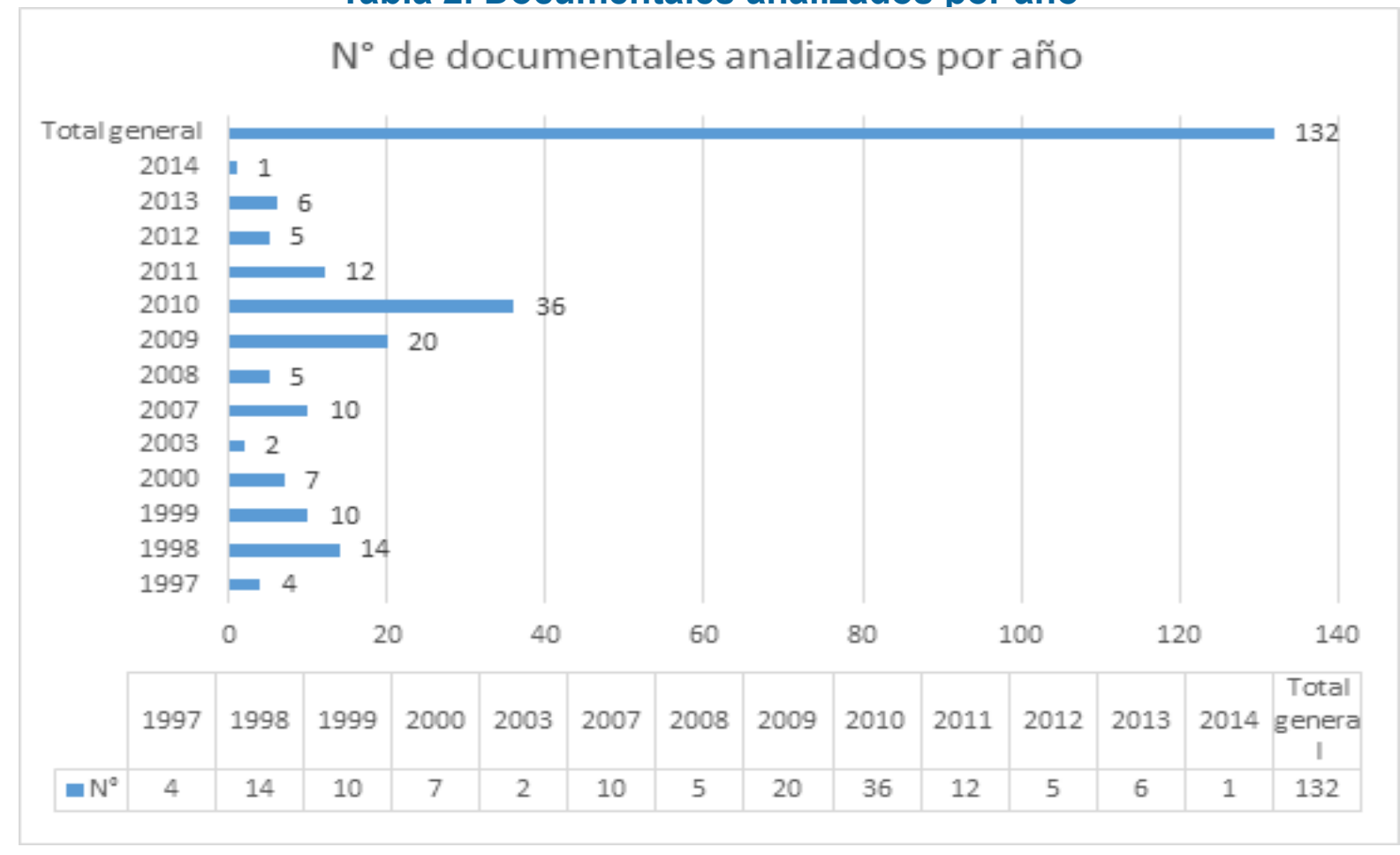

Fuente: elaboración propia 
Uno de los elementos cruciales de la estructura de la televisión pública es su dependencia financiera del estado o entes públicos. Es así como uno los hallazgos significativos del análisis al cruzar las variables de año y número de documentales producidos fue identificar, tanto el gerente del Canal Telemedellín como el alcalde de la ciudad de Medellín durante esos períodos. Lo anterior, porque ello de alguna manera podría haber determinado la priorización de recursos para cierto tipo de contenidos o formatos.

Al realizar ese cruce encontramos que durante ciertas administraciones y gerencias se aumenta la producción del formato documental. Lo anterior es un hallazgo significativo porque gran parte de los recursos de las secretarías del ente municipal se dirigen a la producción de contenidos televisivos en el canal local. Así mismo, pone de manifiesto el interés de ciertos gerentes por producir contenidos documentales en el canal local.

Es así como el período más significativo de producción de documentales es el comprendido entre el 2008 y el 2001, durante la alcaldía de Alonso Salazar y la gerencia del canal de Mauricio Mosquera, con 73 piezas realizadas, que corresponde al $55 \%$ de la muestra total analizada, como se ilustra en la Tabla 3.

Tabla 3. Distribución de producción por gerentes y alcaldes

\begin{tabular}{|c|c|c|c|c|c|c|}
\hline Año & $\mathbf{N}^{\circ}$ & Porcentaje & Gerente & Alcalde & $\begin{array}{l}\text { Por } \\
\text { alcalde }\end{array}$ & Porcentaje \\
\hline 1997 & 4 & $3 \%$ & Ángela Suárez & Sergio Naranjo & 4 & $3 \%$ \\
\hline 1998 & 14 & $11 \%$ & Ángela Suárez- Selene Botero & \multirow{3}{*}{$\begin{array}{l}\text { Juan Gómez } \\
\text { Martínez }\end{array}$} & \multirow[t]{3}{*}{31} & \multirow[t]{3}{*}{$24 \%$} \\
\hline 1999 & 10 & $8 \%$ & $\begin{array}{l}\text { Selene Botero- Carlos Mario } \\
\text { Giraldo }\end{array}$ & & & \\
\hline 2000 & 7 & $5 \%$ & $\begin{array}{l}\text { Carlos Mario Giraldo- Luis } \\
\text { Fernando Calderón }\end{array}$ & & & \\
\hline 2003 & 2 & $2 \%$ & Roger Vélez & $\begin{array}{l}\text { Luis Pérez } \\
\text { Gutiérrez }\end{array}$ & 2 & $2 \%$ \\
\hline 2007 & 10 & $8 \%$ & Berta Lucía Gutiérrez & $\begin{array}{l}\text { Sergio Fajardo } \\
\text { Valderrama }\end{array}$ & 10 & $8 \%$ \\
\hline 2008 & 5 & $4 \%$ & \multirow[t]{4}{*}{ Mauricio Mosquera } & \multirow[t]{4}{*}{ Alonso Salazar } & \multirow[t]{4}{*}{73} & \multirow[t]{4}{*}{$55 \%$} \\
\hline 2009 & 20 & $15 \%$ & & & & \\
\hline 2010 & 36 & $27 \%$ & & & & \\
\hline 2011 & 12 & $9 \%$ & & & & \\
\hline 2012 & 5 & $4 \%$ & \multirow[t]{3}{*}{ Waldir Ochoa Guzmán } & \multirow[t]{3}{*}{ Aníbal Gaviria } & \multirow[t]{3}{*}{12} & \multirow[t]{3}{*}{$10 \%$} \\
\hline 2013 & 6 & $5 \%$ & & & & \\
\hline 2014 & 1 & $0.80 \%$ & & & & \\
\hline $\begin{array}{l}\text { Total } \\
\text { general }\end{array}$ & 132 & & & & & \\
\hline
\end{tabular}

Fuente: elaboración propia 


\section{2 Ámbito de la producción}

En cuanto al ámbito de la producción se encontró que la local tuvo el mayor porcentaje de producción dentro de la muestra analizada, con un $45 \%$, es decir que se abordaron temas de ciudad; mientras que lo regional ocupó un $22 \%$ de la producción, seguido de contenidos dedicados a los barrios con un $18 \%$; mientras que, en una menor proporción, con un $17 \%$, los contenidos abarcan el ámbito internacional y un $8 \%$ nacional. Si sumamos los contenidos locales y barriales encontramos que un $52 \%$ de los documentales analizados se destinan a lo local+barrial, lo que es coherente con los propósitos del canal Telemedellín, que busca el reconocimiento y visibilización de los ciudadanos.

En este caso, si bien el Canal local Telemedellín, tiene como objetivo mostrar la ciudad, también da cuenta de elementos propios de la televisión pública como la universalidad, esto es que los contenidos, si bien pueden tener un componente local, también se dirigen a todos los ciudadanos de un país. (Ver Tabla 4)

Tabla 4. Ámbito de la producción

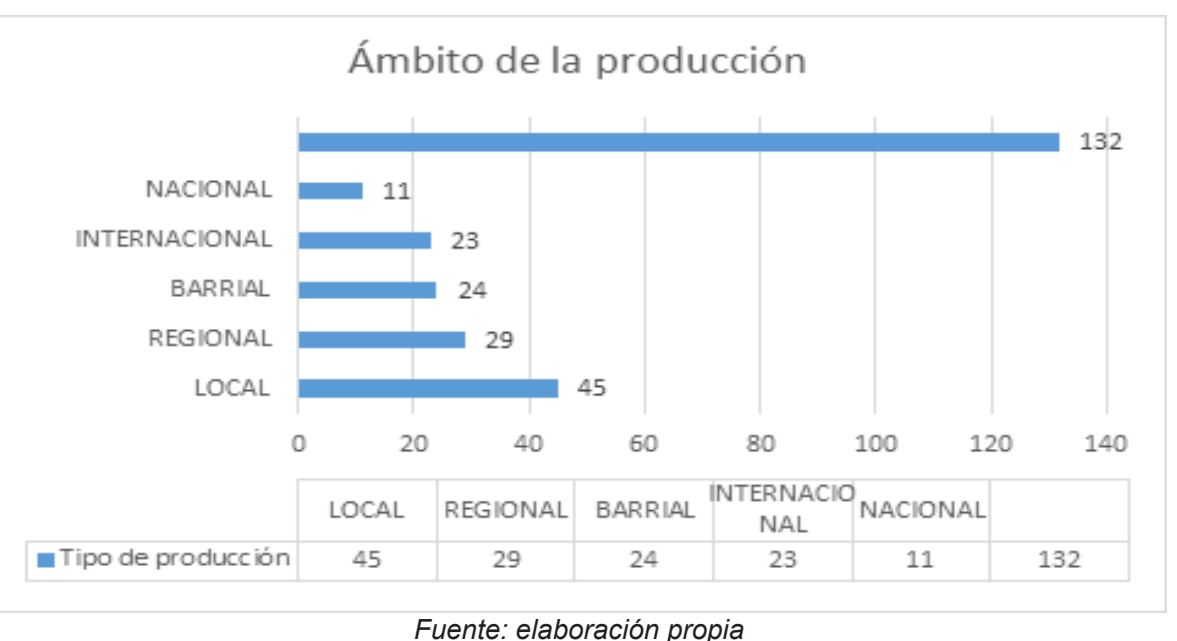

En cuanto a las temáticas abordadas encontramos que el arte, la violencia, los barrios, colombianos en el exterior e historias sobre ciudadanos son los tópicos más abordados, con un $60 \%$. Como se aprecia en la Tabla 5 otros temas están presentes como la historia, el patrimonio, manifestaciones culturales, la democracia, como aspectos clave en el abordaje de contenidos en la televisión pública, lo que resulta significativo porque este tipo de televisión aborda contenidos que la televisión comercial nunca abordará.

Tabla 5. Temas

\begin{tabular}{|l|r|r|}
\hline \multicolumn{2}{|c|}{ Temas } & Porcentaje \\
\hline Arte & 25 & $18 \%$ \\
\hline Violencia & 23 & $17 \%$ \\
\hline Barrios & 20 & $15 \%$ \\
\hline Colombianos en el exterior & 14 & $10 \%$ \\
\hline Ciudadanos & 12 & $9 \%$ \\
\hline Historia de Medellín & 6 & $4 \%$ \\
\hline
\end{tabular}




\begin{tabular}{|l|r|r|}
\hline Deporte & 5 & $3 \%$ \\
\hline Manifestaciones culturales & 4 & $3 \%$ \\
\hline Telemedellín & 3 & $2 \%$ \\
\hline Religión & 3 & $2 \%$ \\
\hline Fenómenos sociales & 2 & $2 \%$ \\
\hline Historia & 2 & $2 \%$ \\
\hline Educación & 2 & $2 \%$ \\
\hline Medio ambiente & 2 & $2 \%$ \\
\hline Planeación urbana & 2 & $2 \%$ \\
\hline Bibliotecas & 1 & $1 \%$ \\
\hline Comunidades indígenas & 1 & $1 \%$ \\
\hline Museos de Medellín & 1 & $1 \%$ \\
\hline Democracia & 1 & $1 \%$ \\
\hline Patrimonio & 1 & $1 \%$ \\
\hline Metro de Medellín & 1 & $1 \%$ \\
\hline Viajes & 1 & $1 \%$ \\
\hline
\end{tabular}

Fuente: elaboración propia

\subsection{Participantes y protagonistas}

El instrumento de análisis permitió identificar y clasificar los participantes de los documentales así: ciudadanos, líderes, expertos y funcionarios.

Al analizar esta variable encontramos que los principales protagonistas y voceros de las historias son los ciudadanos, con un $45 \%$ con participación exclusiva. Es decir, que en 59 de los documentales visualizados, la historia solo se contaba con el testimonio de gente común, con el ciudadano de a pie (Ver Tabla 6). Esto es valioso y significativo a la luz de la teoría que sustenta el deber ser de la televisión pública, es que se dirige al ciudadano más que al consumidor, y que la pantalla posibilita el reconocimiento e identificación de sus audiencias.

La voz del ciudadano se va a combinar también con la mirada de expertos en un $22 \%$, y ciudadanos y líderes en un $12 \%$. Lo anterior también guarda coherencia con la declaración del canal en su eslogan cuando señala que es el canal de la cultura ciudadana y con el actual eslogan Aquí te ves. El formato documental en el Canal Telemedellín es ante todo contado por los ciudadanos, y se evidencia la baja participación de funcionarios como protagonistas en este tipo de contenidos, lo cual es bastante significativo teniendo en cuenta que el canal se financia con recursos de la Alcaldía de Medellín.

Tabla 6. Clasificación de los participantes

\begin{tabular}{|l|r|r|}
\hline Participantes & $\mathbf{N}^{\circ}$ & Porcentaje \\
\hline Solo ciudadanos & 59 & $45 \%$ \\
\hline Ciudadanos y expertos & 22 & $17 \%$ \\
\hline Ciudadanos y líderes & 16 & $12 \%$ \\
\hline
\end{tabular}




\begin{tabular}{|l|r|r|}
\hline Ciudadanos y funcionarios & 4 & $3 \%$ \\
\hline Solo expertos & 3 & $2 \%$ \\
\hline Ciudadanos, líderes y expertos & 3 & $2 \%$ \\
\hline Líderes y funcionarios & 2 & $2 \%$ \\
\hline Otros & 2 & $2 \%$ \\
\hline Solo líderes & 1 & $1 \%$ \\
\hline Expertos y funcionarios & 1 & $1 \%$ \\
\hline Ciudadanos, expertos, líderes y funcionarios & 1 & $1 \%$ \\
\hline Solo funcionarios & 0 & \\
\hline
\end{tabular}

Fuente: elaboración propia

\subsection{Funciones de la televisión pública}

De acuerdo con las funciones propuestas por la Unesco en el ámbito de la televisión pública, el Canal Telemedellín, en lo que se refiere a los contenidos documentales, le apuesta en mayor medida a la función de la diversidad con un $79 \%$, seguido de la universalidad con un $69 \%$, y en menor medida la independencia con un $47 \%$, y la diferenciación con un $31 \%$. (Ver Tabla 7 )

Estas funciones básicamente aluden al desarrollo del contenido. La diversidad y universalidad dan cuenta que el canal hace un esfuerzo por presentar diversos temas de interés para todas audiencias a través de este formato; mientras que en menor medida encontramos la independencia y la diferenciación. En el primer criterio porque de alguna manera ciertos contenidos pierden su objetividad por la dependencia al ente municipal, y en el segundo criterio, porque el formato documental resulta predecible y repetitivo en sus estructuras estéticas y narrativas, y faltan apuestas de contenidos que se destaquen por explorar nuevas formas de contar y abordar las historias.

Tabla 7. Funciones de la Televisión Pública

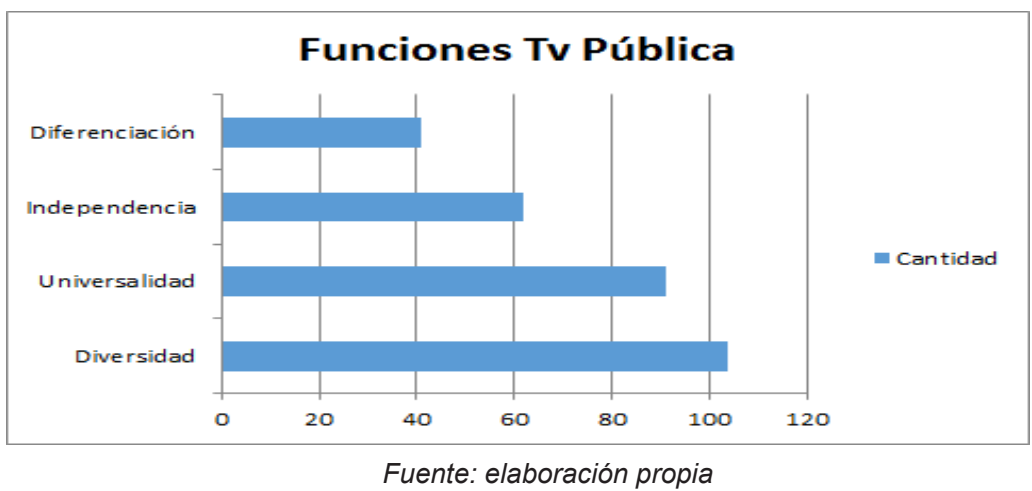

\subsection{Hallazgos relativos al análisis del discurso}

\section{- Situación de enunciación}

En principio nos encontramos, en los documentales visualizados, un privilegio de la voz en off omnisciente y de la función expositiva, explicativa o descriptiva. Cuando se avanza, no obstante, cronológicamente, se empieza a encontrar otras estrategias narrativas en las que se va tomando 
distancia respecto del género periodístico y sus compromisos con la objetividad, dando lugar a otros sujetos y a otras modalidades de la enunciación tales como la experiencia de los personajes, su memoria fragmentaria, dispersa, sesgada si se quiere y ya no necesariamente lineal.

Los relatos no pretenden una mirada acabada de las temáticas y éstas no son necesariamente las más llamativas. El ánimo moralizante y pedagógico pierde protagonismo y entran en juego otros sujetos. Así, los documentales en los que siempre habla la voz de la autoridad: periodistas, presentadores, directores, representantes de la alcaldía, personajes reconocidos, de la política, del arte, de la sociedad antioqueña, de expertos en temas específicos; van dando lugar a otras voces entre las que podemos mencionar: los góticos, los graffiteros, habitantes de la calle y de los barrios, paisas residentes en el extranjero, cantantes de Hip-hop, silleteros, trovadores, víctimas y sobrevivientes, niños, madres, ancianos, activistas de DDHH, maestros, padres de familia, intelectuales, funcionarios públicos y privados, prisioneros, Drag Queens, desplazados.

En relación con lo anterior, es conocida, en la tradición de los estudios sobre el documental, la afirmación de un carácter definido por una función, informativa o didáctica. Esto obedece a la cercanía de buena parte de la producción documental al género periodístico o del reportaje, así como al imperativo de la televisión pública según el cual ésta debe enseñar algo a sus televidentes y tiene su trasfondo, a su vez, en la idea de que el documental debe dar cuenta de lo real que constituye su referente, idea que le separa del cine de ficción que carecería de este compromiso. Con la afirmación y el reconocimiento de estas dos funciones, así como de su recurrencia, no se cubre, no obstante, todo el campo, como también lo saben estos estudios y en este sentido la verificación de tal diversidad de sujetos en el corpus de documentales abordado resultó muy elocuente.

Otro tanto puede decirse de la pregunta por el ¿A quién? Es decir, por los destinatarios. Ya no se trata tan solo de una audiencia pasiva, configurada por aprendices o personas que quieren informarse o ampliar su cultura general y que, por definición, recibirá acríticamente cualquier contenido que se le proponga. Se construye la imagen de un destinatario que a su vez podría ser enunciatario en tanto, como sujeto probable de la experiencia narrada, es a su vez, potencialmente, un sujeto de la enunciación.

Se modifica la relación vertical entre un emisor omnisciente y un receptor que es pasivo y acrítico y se pone de manifiesto el eslogan del canal: "Aquí te ves". Este auditorio está compuesto principal aunque no exclusivamente por ciudadanos de Medellín -que viven o no en la ciudad- y sus municipios aledaños con lo que se manifiesta cierta tendencia de reivindicación de los valores, identidad, conjunto de creencias, experiencias y memoria colectiva. Por otro lado, no obstante, va abriéndose paso, en virtud de los sujetos que, como vimos, toman la palabra, la tendencia a abordar temáticas que no siempre estén en favor de una reivindicación de la tradición y las costumbres paisas y antioqueñas y que den cuenta de otras modalidades de ciudadanía que se construyen desde lugares muy diversos.

En relación con la procedencia de las historias, a la que se alude con la pregunta ¿Desde dónde habla? Es un hallazgo notorio el predominio casi absoluto de la experiencia, a saber, de los diversos sujetos del enunciado. Su experiencia pues, como científicos, desplazados, deportistas, artistas, etc. Es por esto que los recursos más utilizados son la voz en off, el argumento de autoridad, la entrevista, el testimonio, los seguimientos de rutinas, los planos de personajes... Estos recursos subrayan la naturaleza factual, pragmática o experiencial de historias que son contadas por diversos sujetos y, por lo tanto, poseen diversos puntos de vista y no necesariamente obedecen a la estructura del comienzo, el nudo y el desenlace. 
- Dimensiones emocional y racional de la argumentación. Funciones del lenguaje en el documental

En segundo lugar, las perspectivas de análisis que se interrogan por el carácter emocional o racional de la argulmentación (Charaudeau), así como por las funciones del lenguaje (Jakobson) que entran en juego en los documentales de la televisión pública, arrojaron, a su vez, interesantes resultados.

Se confirmó, con la presencia, en un $90 \%$ de los documentales de la función referencial del lenguaje, el privilegio ya mencionado de un sujeto de la enunciación que, por definición se ubica en una postura de superioridad -la del maestro o la del periodista- en todo caso la del que sabe, y que define a buena parte de la producción documental. El privilegio de esta función del lenguaje en el documental, función definida por la exigencia de decir cómo son las cosas, describirlas, enseñarlas, denunciar su naturaleza; y en la que el lenguaje es un instrumento para hablar sobre el mundo, comienza a acompañarse, no obstante, de otro tipo de funciones del lenguaje en el documental. Está, por ejemplo, la función emotiva, en la que argumentación utiliza recursos retóricos, tanto racionales como emocionales. Así, son frecuentes las frases conmovedoras, pronunciadas por los diversos sujetos del enunciado, así como un uso retórico de la imagen y de la música. Así, un $78 \%$ de los documentales observados posee esta función emotiva, lo que da cuenta, también, de un desplazamiento de la exigencia de objetividad hacia la intimidad.

Otro hallazgo importante tiene que ver con la función conativa. El $86 \%$ de los documentales no utiliza esta función, lo cual da cuenta de que, entre los recursos retóricos, no son muy utilizados el diálogo o la interpelación directa a personajes o incluso al auditorio, sino que, a pesar de lo que hemos mencionado sobre inclusión de personajes y aspectos emocionales, sigue habiendo un cuidadoso gobierno del sujeto que enuncia y poco uso de la interacción.

La función metalingüística, mediante la cual el discurso se vuelve sobre sí mismo, se hace autorreferencial, tiene una presencia escasa en el corpus visualizado, tan solo el $26 \%$ de los documentales la utilizan. Esto confirma el primero de los hallazgos respecto de la función referencial. Los documentales están más orientados a describir o a explicar el mundo, que a una reflexión sobre el documental mismo y sus modalidades expresivas. Este porcentaje, no obstante, da cuenta de una tendencia autorreflexiva que no resulta despreciable, toda vez que da cuenta de que el documental, aún en la televisión pública, está lanzando una mirada crítica sobre sí mismo.

La función fática, que básicamente consiste en una verificación de las condiciones de la comunicación, tiene, como era de esperarse, una presencia débil en los documentales observados, tan solo el $17 \%$ la utiliza.

Por último, lo cual resulta importante, está la presencia que verificamos de la función poética. Un $46 \%$ de documentales la utilizan, lo cual resulta llamativo, toda vez que da cuenta del fortalecimiento, en el documental, de una tendencia estética, creativa, que quizá tenga que ver con la autonomía de algunas de estas producciones, respecto de funciones pedagógicas, de denuncia, propaganda o descripción detallada y objetiva del mundo. La función poética es manifestación de autonomía respecto de las urgencias de lo contingente y de experimentación en otras narrativas.

\section{- Hallazgos relativos al tipo de documental}

El análisis del corpus documental y la aplicación del instrumento en cuanto a su clasificación categórica referida a la teoría propuesta por Nichols, da como resultado que 96 de los documentales 
equivalente al $73 \%$ cuentan con un carácter expositivo, usando el recurso de la voz de un narrador como hilo conductor del relato, mientras que las imágenes son presentadas como un mecanismo ilustrativo de la palabra. Este carácter expositivo es complementado con un carácter reflexivo, invitando al espectador a plantearse preguntas sobre las problemáticas presentadas, esta tipología está presente en 63 documentales lo que corresponde a un $48 \%$ del corpus documental.

Las demás categorías analizadas cuentan con una presencia muy baja. La categoría observacional en donde el director intenta no intervenir en la escena, sólo se encuentra presente en 10 documentales equivalente a un $8 \%$, al igual que componente poético en el cual se desarrollan hechos del mundo histórico a través de imágenes fragmentadas o menos literales. Esta característica se encuentra presente en 11 de los documentales. Los rasgos de documental performativo cuenta con una presencia del $5 \%$ evidenciada en 6 documentales y los documentales con características etnográficas son aún menos presentes con un 3\% evidenciado en 4 documentales, en cuanto al documental con características web sólo se evidencia en un 1\%. (Ver tablas 8, 9, 10)

Tabla 8. Caracterización del tipo de documental expositivo

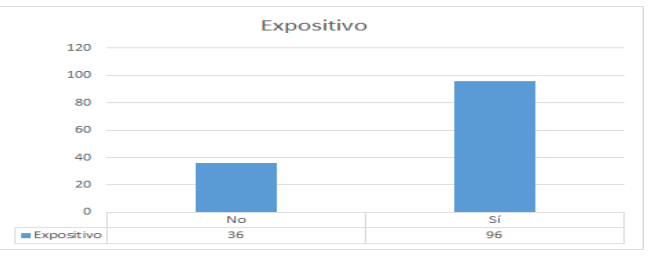

Tabla 9. Caracterización del tipo de documental reflexivo

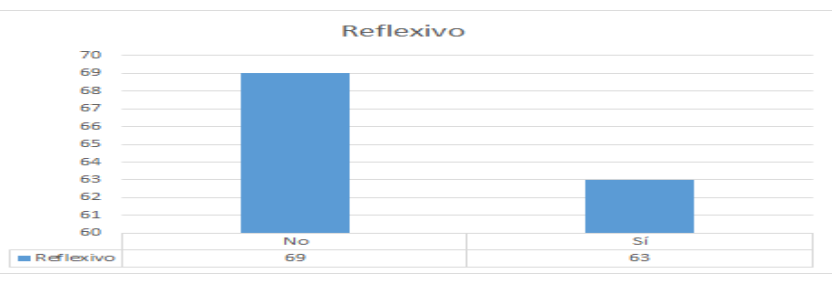

Tabla 10. Caracterización general tipos de documental

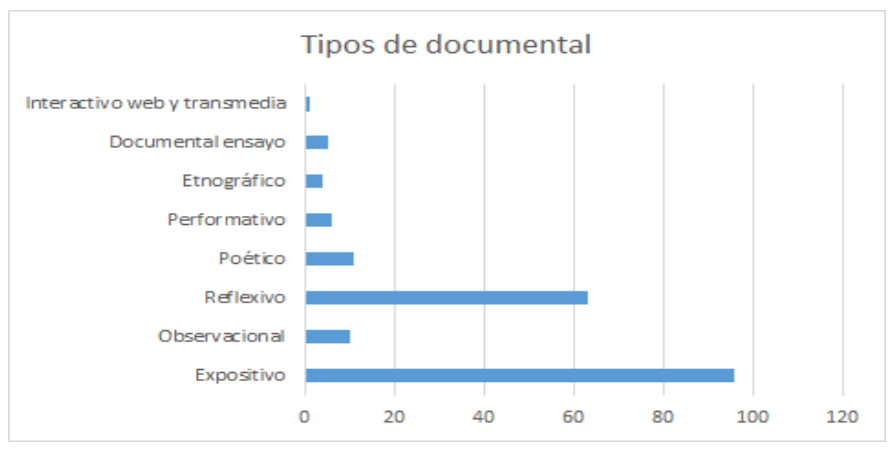




\section{Conclusiones}

Siendo la función referencial la que más privilegia el corpus de documentales que hemos analizado, también se pone en evidencia una incipiente toma de distancia respecto de la función meramente instrumental del lenguaje, y por lo tanto de sus funciones didáctica, moralizante, expositiva o propagandística.

Los destinatarios del documental ya no son solo quienes están en condiciones de ser informados o de aprender. Paulatinamente va instalándose en los documentales la imagen de un destinatario que es, a su vez, un enunciatario potencial.

En relación con la procedencia de los contenidos llama la atención el hallazgo de que, en lo fundamental, coincide con una pluralidad de experiencias que se manifiestan en testimonios, fuentes bibliográficas, argumentos de autoridad de expertos o personas que han vivido determinadas situaciones.

Es escasa la presencia, en los documentales, de la función metalingüística, es decir, de una reflexión, desde el documental, sobre el documental mismo, o bien, de un autorreflexión. Sin embargo, se encuentran documentales que tienen este propósito.

Los documentales analizados en su mayoría cuentan con un desarrollo de orden expositivo en donde el hilo conductor es llevado por una voz y las imágenes operan de forma ilustrativa, esta condición evidencia que las búsquedas narrativas son limitadas y reproducen las formas tradicionales a la hora de estructurar los relatos. Los documentales cuentan en menor medida con la presencia de otras categorías como la reflexiva, sin embargo, no es representativa dentro del corpus de los documentales estudiados. Lo anterior genera no sólo una ausencia de la presencia de las categorías, sino una forma interpretativa a la hora de contar las realidades de la ciudad, careciendo del uso de la cámara como un elemento que presente en las acciones desde lo observacional, o elemento participativo proveniente del documental etnográfico, abriendo una puerta hacia la búsqueda o implementación de nuevas narrativas interactivas, web y transmedia.

El documental en el Canal Telemedellín es un formato que se acerca y cumple con las funciones de la televisión pública de diversidad, universalidad, independencia y diferenciación. Es así como en su trayectoria como canal de televisión le ha apostado a este formato de manera permanente, y los contenidos han reflejado el reconocimiento de los ciudadanos como protagonistas de las historias, y se cumple con la declaración de sus propósitos: El Canal de la Cultura Ciudadana, y Aquí te ves.

El instrumento de análisis para contenidos documentales en la televisión pública es una propuesta que permite sistematizar y caracterizar los programas y contenidos audiovisuales tanto desde la parte formal, es decir desde el formato y las características de un programa de televisión o contenido audiovisual, así como desde los recursos narrativos empleados. Su implementación en canales de televisión o en la sistematización de contenidos permite ampliar las categorías que posibiliten obtener un detalle más profundo del tipo de contenidos, participantes y perspectiva del discurso recurrentes utilizados. Este instrumento tiene múltiples perspectivas de análisis y puede ser utilizado en diferentes corpus audiovisuales. 


\section{Bibliografía}

ANTV (2015) Informe anual del sector. Junio de 2016. Disponible en: https://www.antv.gov.co/ANTV GOV/ HTML/INFORM-2.HTM (Recuperado el 5 de agosto de 2016)

Ardèvol, E. (1998) Por una antropología de la mirada: Etnografía, representación y construcción de datos audiovisuales. Revista de Dialectología y Tradiciones Populares del CSIC. L. Calvo, Perspectivas de la antropología visual. Madrid.

Barker, C. (2003). Televisión, globalización e identidades culturales. Barcelona: Paidós.

Burke, P. (2001) Visto y no visto. El uso de la imagen como documento histórico, Crítica, Barcelona.

Castaño, A; Cardona, C. (2012) Análisis de la interactividad del modelo convergente de televisión e internet de Telemedellín 2.0 desde la comunicación digital interactiva. Informe de investigación, Universidad de Medellín, Facultad de Comunicación.

Charaudeau, P. (2011) Las emociones como efectos del discurso. En: revista Versión, n. ${ }^{\circ}$ 26, junio 2011. La experiencia emocional y sus razones, pp. 97-118, UAM, México, 2011. En: https://biblat.unam.mx/es/ revista/version-mexico-d-f/articulo/las-emociones-como-efectos-de-discurso-traduccion-de-ma-de-lourdesberruecos-villalobos

Cock, A. (2010) Realidad desdibujada. Disponible en: http://docuscolombia.blogspot.com/p/documentosteoria-documental.html (Recuperado el 1 de agosto de 2016)

Dahlgren, P. (1995). Television and the public sphere: citizenship, democracy and the media. Londres: Sage.

Dahlgren, P. (1997). El espacio público y los medios. ¿Una nueva era? En I. Veirat-Masson, \& D. Dayan, Espacios públicos en imágenes. Barcelona: Gedisa.

Dahlgren, P. (2009). Media and Political Engagement. Citizens, Communication and Democracy. Nueva York: Cambridge University Press.

Fuenzalida, V. (2000). La Televisión Pública en América Latina: Reforma o privatización. Santiago: Fondo de Cultura Económica.

Gifreu, A. (2012). El documental interactivo y transmedia. Disponible en: http://agifreu.com/interactive documentary/TesisArnauGifreu2012.pdf (Recuperado el 5 de agosto de 2016)

Igárzabal, B. (2013) Por una televisión pública con audiencia. Págs. 51-64. En: Rincón, O. (Ed.). Zapping Tv. El paisaje de la tele latina. Bogotá: Friedrich Ebert Stiftung FES Comunicación

Jakobson, R. (1981). Lingüística y poética. Madrid: Cátedra.

Keane, J. (1985). The politics of broadcasting. Sidney: Taylor \& Francis.

Keane, J. (1997). Transformaciones estructurales de la esfera pública. Estudios Sociológicos del Colegio de México , 47-77.

Livingstone, S., \& Lunt, P. K. (1994). Talk on television: audience participation and public debate. Nueva York: Routledge.

López, J. A. Diciembre de 2011. El documental de los años sesenta como arte: consideraciones de la película Crónica de un verano. Palabra Clave 14 (2), 235-246. 
Martín Barbero, J., Rincón, O., \& Rey, G. (2000). Televisión pública, cultural, de calidad. Gaceta , 50-61.

Mazzioti, N. (2005) Los géneros en la televisión pública. En: Rincón, O (Ed). Televisión pública: del consumidor al ciudadano. (Pág. 181-207) Buenos Aires: La Crujía Ediciones.

Nichols, B. (1996) La representación de la realidad. Barcelona: Paidós: Barcelona.

Rabiger, M. (2005) Dirección de documentales, Instituto oficial de Radio y Televisión, RTVE. Madrid.

Ricœur, P. (2000) La memoria, la historia y el olvido, Siglo XXI, Madrid.

Rincón, O. (Ed) (2005). Televisión pública: del consumidor al ciudadano. Buenos Aires: La Crujía Ediciones.

Rincón, O (2006). Narrativas Mediáticas. O cómo se cuenta la sociedad del entretenimiento. Barcelona: Gedisa. 2006.

Silva Rodriguez, Manuel, Kuéllar Diana (2015) Documental (es) Voces... Ideas. Cali: Programa Editorial Universidad del Valle.

Thompson, J. B. (1996). La teoría de la esfera pública. Voces y culturas , 81-96.

Keane, J. (1998). Los media y la modernidad. Una teoría de los medios de comunicación. Barcelona: Paidós.

Unesco. (2006). Radiotelevisión de servicio público: un manual de mejores prácticas. San José: UNESCO.

Valle, M., Gómez Sánchez, S., Restrepo, J., Gómez, J., \& Raigosa, W. (2019). Documentales y documentalistas Antioqueños. Sentido y práctica de un oficio que narra una región. LUCIÉRNAGA, 11(21), 5 - 39. doi: https:// doi.org/10.33571/revistaluciernaga.v11n21a1

Waisbord, S. (2000). Industria global, culturas y políticas locales: la internacionalización de la televisión latinoamericana. AméRica Latina Hoy, 25. Recuperado de https://revistas.usal.es/index.php/1130-2887/ article/view/2668

Telemedellín (2012) M. Quince años de vida, de historias y personajes Quince años de ciudad. Disponible en: https://issuu.com/telemedellin/docs/telemedellin Recuperado el 5 de agosto de 2016.

\section{Para citar este artículo:}

Alzate, A., Maya, C., Heredia, V., (2020). El documental en el contexto de la televisión pública. Categorías para su análisis. Revista Luciérnaga Comunicación. Vol. 12, Núm. 23.Pp 130-149. https://doi.org/10.33571/revistaluciernaga.v12n23a6

Ojs: https://revistas.elpoli.edu.co/index.php/luc/issue/archive

Link. https://www.politecnicojic.edu.co/index.php/revista-luciernaga 